\title{
Traumatic posterior communicating artery- cavernous fistula, angioarchitecture, and possible pathogenesis: a case report and literature review
}

This article was published in the following Dove Press journal:

Neuropsychiatric Disease and Treatment

30 March 2016

Number of times this article has been viewed

\author{
Bin $\mathrm{Du}^{1}{ }^{1, *}$ \\ Meng Zhang',* \\ Qing-Lin Liu \\ Jie Shen ${ }^{2}$ \\ Yun-Yan Wang ${ }^{2}$ \\ 'Department of Neurosurgery, \\ Jinan Central Hospital Affiliated to \\ Shandong University, ${ }^{2}$ Department \\ of Neurosurgery, Qi Lu Hospital, \\ Shandong University, Jinan, People's \\ Republic of China \\ *These authors contributed equally \\ to this work
}

\begin{abstract}
Carotid-cavernous fistulas (CCFs) are an abnormal vascular shunt between the carotid artery and the cavernous sinus, and were traditionally classified into four subtypes based on the detailed fistulas anatomy and arterial supply. CCFs are frequently encountered in patients with traumatic skull base fractures. In this report, we present one such case caused by two head traumas. Computed tomography and digital subtraction angiography confirmed that this CCF arose from posterior communicating artery of the internal carotid artery, which is not included in the traditional Barrow et al's categorization. The possible mechanisms include laceration of dural mater of posterior clinoid process and laceration or pseudoaneurysm formation of posterior communicating artery. This case was successfully treated with endovascular coil embolization.

Keywords: carotid-cavernous fistulas, cavernous sinus, CCF, PComA, posterior communicating artery
\end{abstract}

\section{Introduction}

Carotid-cavernous fistulas (CCFs) are one type of abnormal vascular shunt, which allow blood to flow directly or indirectly from the carotid artery to the cavernous sinus. CCFs were first classified into four subtypes by Barrow et al in 1985 based on the detailed fistulas anatomy and arterial supply. ${ }^{1}$ Type A CCF is referred to the direct high-flow shunt from the internal carotid artery (ICA) to the cavernous sinus. ${ }^{2}$ Other three subtypes involve the shunts from meningeal branches of ICA (Type B), of the external carotid artery (Type C), or of both (Type D) to the cavernous sinus. Posterior communicating artery (PComA)-cavernous fistulas are outside the Barrow's categorization, ${ }^{3}$ and are rare complications of craniofacial trauma. In this report, we presented one such CCF intercommunicating between the left PComA and the cavernous sinus, which was caused by two head traumas. This case was diagnosed with multiple examinations and was successfully treated with endovascular coil embolization. This study was approved by the ethics committee of Shandong University, and this patient provided signed written informed consent.

\section{Case report}

A 30-year-old male complaining of progressive conjunctival congestion and strabismus on his left eye for 6 months was admitted to our hospital. This patient suffered a severe head injury 18 months ago. This injury recovered well after decompressive craniotomy and evacuation of intracranial hematoma. This patient was also given a cranioplasty for his skull defect 3 months after his injury. However, 1 year after the head injury, he had another head injury and got expectant treatment at this time.
Correspondence: Yun-Yan Wang Department of Neurosurgery, Qi Lu Hospital, Shandong University, No 107, Wenhua Xi Road, Jinan 2500I2, People's Republic of China Tel +8653182166620 Fax +86 53I 82I6 66I5 Email wangyunyan0618@yeah.net
Neuropsychiatric Disease and Treatment 2016:12 707-7II

707

Dovepress

http://dx.doi.org/1 0.2147/NDT.S96588 (c) (1) (5) 2016 Du et al. This work is published and licensed by Dove Medical Press Limited. The full terms of this license are available at https://www.dovepress.com/terms.php

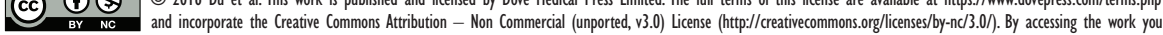
hereby accept the Terms. Non-commercial uses of the work are permitted without any further permission from Dove Medical Press Limited, provided the work is properly attributed. For permission for commercial use of this work, please see paragraphs 4.2 and 5 of our Terms (https://www.dovepress.com/terms.php). 

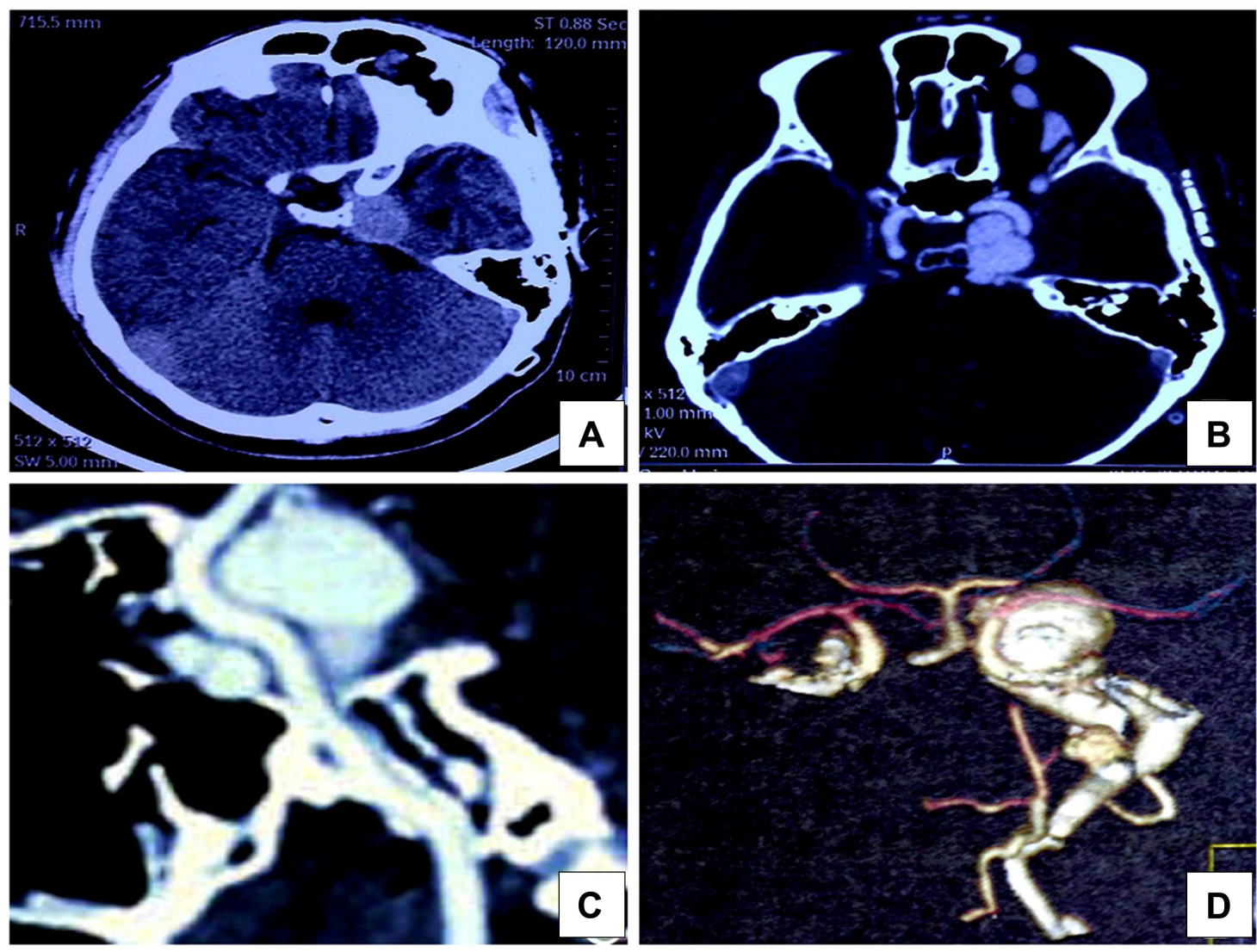

Figure I CT and CTA images before treatment.

Notes: (A) CT axial scanning reveals a hyperdensity mass on the left of sella turcica. (B) CT contrast scanning reveals enhancement of the parasella mass and dilatation and tortuosity of the left superior ophthalmic vein. (C) CTA image of anterior-posterior projection reveals an enhanced mass at the posterior wall of ICA and enlarged ophthalmic vein. (D) CTA reconstruction image reveals an enhanced mass at the lateral wall of left ICA-associated CCF and the drainage vein.

Abbreviations: CT, computed tomography; CTA, computed tomography angiography; ICA, internal carotid artery; CCF, carotid-cavernous fistula.

On admission to our hospital, physical examinations revealed chemosis, orbital bruits, and incomplete abducens dysfunction on his left eye. No visual disturbance was seen. Computed tomography and computed tomography angiography scanning revealed a high-density mass in the left cavernous sinus, which was obviously enhanced after injection of contrast material (Figure 1). Cerebral digital subtraction angiography, three-dimensional angiography, and superselective angiography via a microcatheter clarified the angioarchitecture of this CCF (Figure 2). The three-dimensional angiography revealed that the supplying artery had an arterial lumen of $2 \mathrm{~mm}$ and originated from the $\mathrm{C} 1$ segment of ICA, which was identified as PComA due to its origination from posterior-medial wall of ICA and $2 \mathrm{~mm}$ interior diameter.

This patient was treated with coils via transarterial approach. A 6 F Envoy (Codman, Raynham, MA, USA) guiding catheter was placed in the left cervical ICA, and then an Echalon 10 microcatheter (EV3, Plymouth, MN, USA) with the Silverspeed 0.014 microwire (EV3) was superselectively introduced into the ectasia of the cavernous fistula through the ICA and the PComA. Detachable platinum coils (Axium, EV3; $20 \mathrm{~mm} \times 50 \mathrm{~cm}, 20 \mathrm{~mm} \times 50 \mathrm{~cm}$, $20 \mathrm{~mm} \times 50 \mathrm{~cm}, 18 \mathrm{~mm} \times 40 \mathrm{~cm}, 18 \mathrm{~mm} \times 40 \mathrm{~cm}, 16 \mathrm{~mm} \times 40 \mathrm{~cm}$, $16 \mathrm{~mm} \times 40 \mathrm{~cm}$ ) were inserted into the pouch of the cavernous sinus through this microcatheter. After compact embolization of the cavernous sinus, Axium coils $(2 \mathrm{~mm} \times 8 \mathrm{~cm}$, $2 \mathrm{~mm} \times 6 \mathrm{~cm}, 1.5 \mathrm{~mm} \times 2 \mathrm{~cm}$ ) were delivered and detached to occlude the PComA. Angiography was performed subsequent to embolization and showed complete occlusion of CCF (Figure 3). Orbital bruits immediately disappeared after operation. Conjunctival congestion and strabismus also disappeared 2 days later.

\section{Discussion}

Traumatic CCFs most commonly occur as a result of head injury-associated skull base bone fracture or puncture injury. ${ }^{4,5}$ The damage of the posterior part of the sphenoid bone, the internal part of orbit wall, the ethmoid sinus, and the ethmoid bone is the key point of traumatic CCF formation. Dural mater covers the superior, lateral, and medial surfaces 

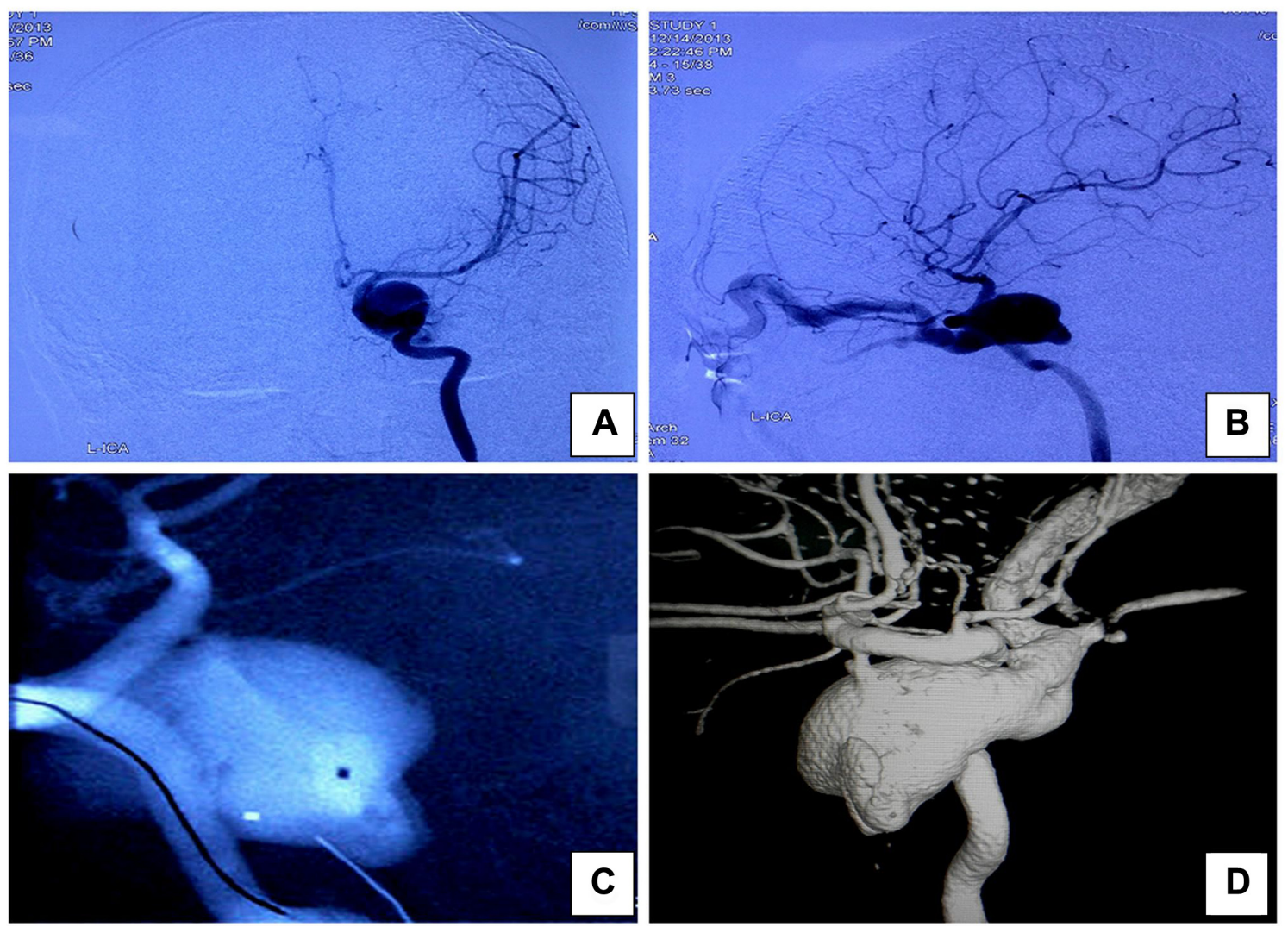

Figure 2 DSA images before treatment.

Notes: (A) Frontal and (B) lateral angiographic projection of left ICA demonstrates CCF. (C) Microcatheter enters the pouch of the cavernous sinus through the supraclinoid ICA and the PComA. (D) Three-dimensional angiography demonstrates the relationship between the PComA and CCF.

Abbreviations: DSA, digital subtraction angiography; ICA, internal carotid artery; CCF, carotid-cavernous fistula; PComA, posterior communicating artery.

of the cavernous sinus, whereas the inferior surface is formed by the middle cranial fossa. Umansky et $\mathrm{al}^{6}$ divided the roof of the cavernous sinus into three regions: the oculomotor trigone, the carotid trigone, and the clinoid space. The cranial base fracture may lacerate the dural mater constituting of the cavernous sinus; also, sharp bone fragment can directly penetrate the ICA and the meningeal artery.

CCFs are abnormal vascular shunt between carotid artery and the cavernous sinus. Based on the different supplying arteries, Barrow et al categorized CCFs into four subtypes. While Type A CCF is a direct communication between the cavernous sinus and ICA, the other three subtypes (Types B, $\mathrm{C}$, and D) are indirect fistulas, in which dural arteriovenous fistulas are fed by the dural branches of ICA, external carotid artery, or both. ${ }^{7}$ Traumatic CCF with the supplying artery of PComA or intradural ICA has not been reported. Anatomically, PComA does not contact with the dural mater of the cavernous sinus. ${ }^{8}$ Usually, PComA runs adjacent to the dural mater of the posterior clinoid process; sometimes, it is fixed to these structures by arachnoid membrane. The arachnoid membrane immobilizes PComA to the dural mater of the skull base, especially the dural mater covering the posterior process and the cavernous sinus. ${ }^{9}$ PComA also ran in the bony superfissure on the surface of posterior process in rare case. ${ }^{9}$ In oculomotor triangle, PComA may cross between the supratentorial and the infratentorial spaces or between the anterior and posterior petroclinoid folds. ${ }^{410}$ Theoretically, fracture of the posterior process may result in laceration of dural mater of this area. If PComA or PComA aneurysm ruptures simultaneously, a shunt forms between the PComA and the cavernous sinus. In the present study, this patient suffered two severe head injuries and craniotomy. During the first head trauma or surgery, the PComA may be damaged, and a pseudoaneurysm may form and adhere to the posterior clinoid process. The shunt may not appear in the first head trauma due to the local adhesion and the capsulation of hematoma and other tissues. In the second head injury, the damaged dural mater may be lacerated again, and then the shunt may form between the PComA pseudoaneurysm and the cavernous sinus. The PComA adhered to the dural mater of the posterior process can also be lacerated, and the laceration may form a communication with the cavernous sinus. 

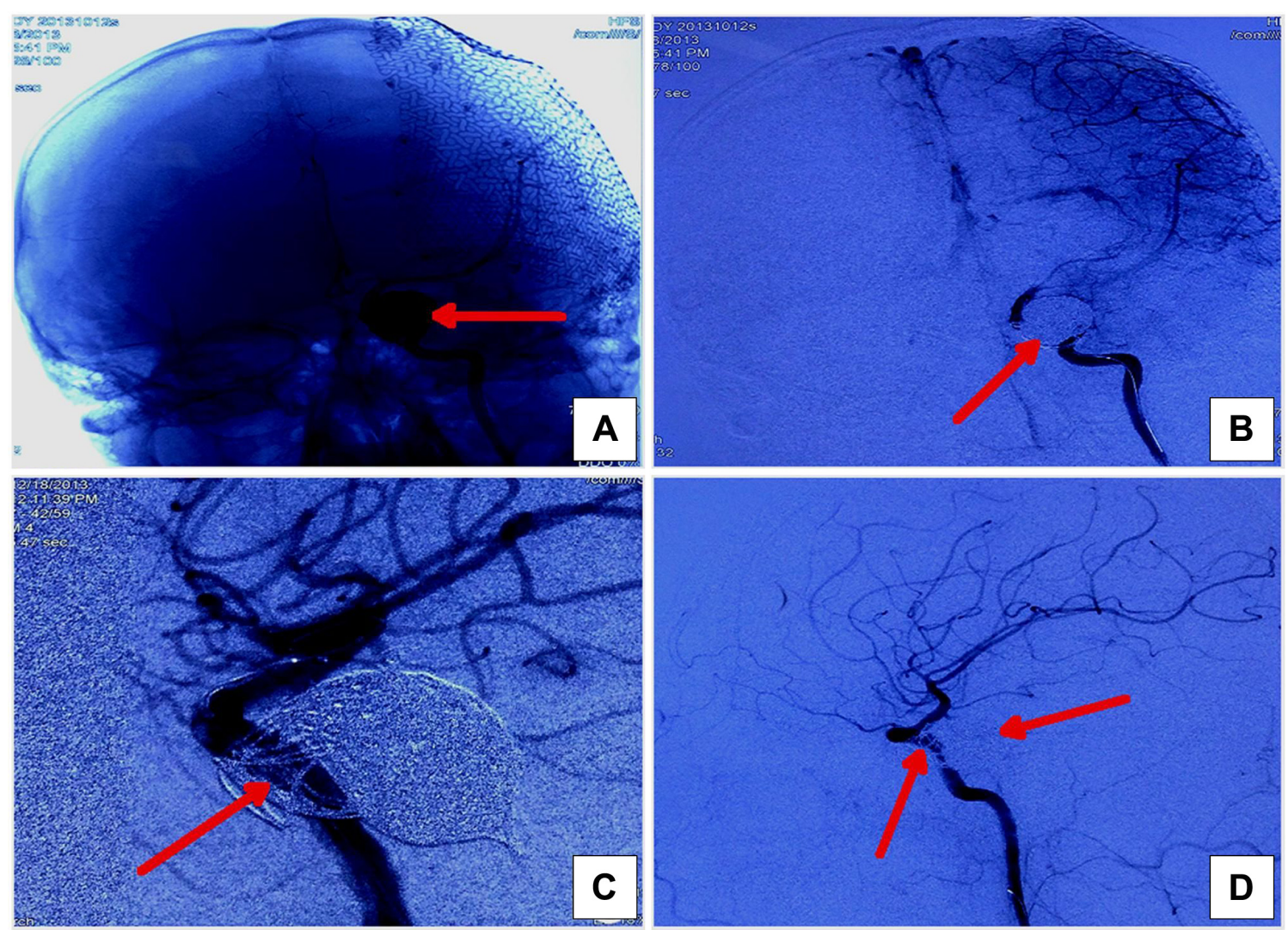

Figure 3 Post-embolization DSA images after endovascular embolization.

Notes: (A and B) Anterior-posterior projection. (C and $\mathbf{D})$ Lateral projection. DSA of the left ICA reveals obliteration of the fistula and no residual filling of the CS in late venous phase. The red arrows indicate detachable platinum coils delivered into the pouch of the cavernous sinus.

Abbreviations: DSA, digital subtraction angiography; ICA, internal carotid artery; CS, cavernous sinus.

The advances of endovascular technology such as detachable balloon, detachable platinum coils, and other embolic materials have provided many options for the treatment of the cavernous fistula. Traditional surgery has been rarely used in direct CCFs due to its potential risk to the brain. ${ }^{11-14}$ As an alternate, the endovascular approach has become the major option for CCFs' treatment. In this case, we occluded the PComA using detachable platinum coil and obatined satisfactory result. The detachable platinum coil has some advantages such as reliable and controlled deployment. ${ }^{11}$ Even if the placement of the coil is not satisfactory, it can be replaced or removed easily and safely. Covered stents ${ }^{15,16}$ and flow-diverting stents ${ }^{17,18}$ are being used as another alternative methods for CCFs treatment. If there is no artificial cranioplasty history, this patient can also be treated by clipping the PComA via craniotomy.

\section{Conclusion}

This case is a new subtype of traumatic CCF, which is beyond the traditional Barrow's categorization. The supplying artery is PComA. The possible mechanisms of CCF formation include two aspects: laceration of dural mater of the posterior clinoid process and laceration or pseudoaneurysm formation of PComA during head trauma. Endovascular coil embolization is an effective treatment for this selected patient.

\section{Acknowledgments}

This study was granted by the National Natural Scientific Foundation of China (No 81141088) and the Promotive Research Fund for Excellent Young and Middle-Aged Scientists of Shandong Province (No 2004BS02010).

\section{Disclosure}

The authors disclose that there was no sponsorship or funding arrangements related to this study and report no conflicts of interest in this work.

\section{References}

1. Barrow DL, Spector RH, Braun IF. Classification and treatment of spontaneous carotid-cavernous sinus fistulas. J Neurosurg. 1985;62(2): 248-256.

2. Conforti R, Cirillo M, Marrone V, et al. Giant thrombosed intracavernous carotid artery aneurysm presenting as Tolosa-Hunt syndrome in a patient harboring a new pathogenic neurofibromatosis type q mutation: a case report and review of the literature. Neuropsychiatr Dis Treat. 2014;10: $135-140$. 
3. Cigoli MS, De Benedetti S, Marocchi A, et al. A novel MGC4607/ CCM2 gene mutation associated with cerebral spinal and cutaneous cavernous angiomas. J Mol Neurosci. 2015;56(3):602-607.

4. Liang W, Xiaofeng Y, Weiguo L, Wusi Q, Gang S, Xuesheng Z. Traumatic carotid cavernous fistula accompanying basilar skull fracture: a study on the incidence of traumatic carotid cavernous fistula in the patients with basilar skull fracture and the prognostic analysis about traumatic carotid cavernous fistula. J Trauma. 2007;63(5):1014-1020.

5. Helmke K, Krüger O, Laas R. The direct carotid cavernous fistula: a clinical, pathoanatomical, and physical study. Acta Neurochir (Wien). 1994;127(1):1-5.

6. Umansky F, Valarezo A, Elidan J. The superior wall of the cavernous sinus: a microanatomical study. J Neurosurg. 1994;81(6):914-920.

7. EI-Hindy N, Kalantzis G, Patankar T, et al. Difficult indirect carotidcavernous fistulas-alternative techniques to gaining access for treatment. Clin Interv Aging. 2014;9:1687-1690.

8. Yu J, Shi Z, Lv M, Yang X, Wu Z. A poorly treated carotid-cavernous fistula rescued by coils through a PComA approach. A case report. Interv Neuroradiol. 2009;15(1):197-201.

9. Gonzalez-Darder JM, Quilis-Quesada V, Talamantes-Escriba F, BotellaMacia L, Verdu-Lopez F. Microsurgical relations between internal carotid artery-posterior communicating artery (ICA-PComA) segment aneurysms and skull base: an anatomoclinical study. J Neurol Surg B. 2012;73(5):337-341.

10. Weber W, Henkes H, Berg-Dammer E, Esser J, Kühne D. Cure of a direct carotid cavernous fistula by endovascular stent deployment. Cerebrovasc Dis. 2001;12(3):272-275.
11. Gupta AK, Purkayastha S, Krishnamoorthy T, et al. Endovascular treatment of direct carotid cavernous fistulae: a pictorial review. Neuroradiology. 2006;48(11):831-839.

12. Gemmete JJ, Ansari SA, Gandhi D. Endovascular treatment of carotid cavernous fistulas. Neuroimaging Clin N Am. 2009;19(2):241-255.

13. Ellis JA, Goldstein H, Connolly ES, Meyers PM. Carotid-cavernous fistula. Neurosurg Focus. 2012;32(1):E9.

14. Korkmazer B, Kocak B, Tureci E, Islak C, Kocer N, Kizilkilic O. Endovascular treatment of carotid cavernous sinus fistula: a systematic review. World J Radiol. 2013;5(4):143-155.

15. Wang YL, Ma J, Ding PX, Li YD, Han XW, Wu G. Treatment of posttraumatic carotid-cavernous fistulas with the Willis covered stent. A preliminary prospective study. Interv Neuroradiol. 2012;18(2):172-177.

16. Yin B, Sheng HS, Wei RL, Lin J, Zhou H, Zhang N. Comparison of covered stents with detachable balloons for treatment of posttraumatic carotid-cavernous fistulas. J Clin Neurosci. 2013;20(3):367-372.

17. Nadarajah M, Power M, Barry B, Wenderoth J. Treatment of a traumatic carotid-cavernous fistula by the sole use of a flow diverting stent. J Neurointerv Surg. 2012;4(3): e1.

18. Paiva WS, Fonoff ET, Marcolin MA, Bor-Seng-Shu E, Figueiredo EG, Teixeira M. Navigated transcranial magnetic stimulation in preoperative planning for the treatment of motor area cavernous angiomas. Neuropsychiatr Dis Treat. 2013;9:1885-1888.
Neuropsychiatric Disease and Treatment

\section{Publish your work in this journal}

Neuropsychiatric Disease and Treatment is an international, peerreviewed journal of clinical therapeutics and pharmacology focusing on concise rapid reporting of clinical or pre-clinical studies on a range of neuropsychiatric and neurological disorders. This journal is indexed on PubMed Central, the 'PsycINFO' database and CAS,

\section{Dovepress}

and is the official journal of The International Neuropsychiatric Association (INA). The manuscript management system is completely online and includes a very quick and fair peer-review system, which is all easy to use. Visit http://www.dovepress.com/testimonials.php to read real quotes from published authors. 